\title{
Formation of Low Acetyl Content Cellulose Acetate Membrane for $\mathrm{CO}_{2} / \mathrm{N}_{2}$ Separation
}

\author{
Lavania Sugu and Zeinab Abbas Jawad* \\ Department of Chemical Engineering, Faculty of Engineering and Science, \\ Curtin University Malaysia, CDT 250, 98009 Miri, Sarawak, Malaysia \\ *Corresponding author: zeinab.aj@curtin.edu.my
}

Published online: 25 April 2019

To cite this article: Sugu, L. \& Jawad, Z. A. (2019). Formation of low acetyl content cellulose acetate membrane for $\mathrm{CO}_{2} / \mathrm{N}_{2}$ separation. J. Phys. Sci., 30(1), 111-125, https:// doi.org/10.21315/jps2019.30.1.9

To link to this article: https://doi.org/10.21315/jps2019.30.1.9

\begin{abstract}
The rising carbon dioxide $\left(\mathrm{CO}_{2}\right)$ emissions over the decades is known to be a huge contributor to the greenhouse effect. $\mathrm{CO}_{2}$ capture and storage methods have been perceived as favourable solutions to prevent global warming and climate change rising from the greenhouse effect. One energy efficient technology for separating $\mathrm{CO}_{2}$ is the development of high-performing $\mathrm{CO}_{2}$ gas separating membranes. A variety of membrane-based gas separation technologies designed have shown promising results and are inexpensive. A high-performing membrane must have a defect-free, thin dense skin-layer with a porous sub-layer for support that permits great permeation rate and selectivity. Of all ranges of polymers used to make polymeric membranes for $\mathrm{CO}_{2}$ /nitrogen $\left(\mathrm{N}_{2}\right)$ separation, cellulose acetate $(\mathrm{CA})$ polymer membranes are known for their high $\mathrm{CO}_{2}$ solubility. In this research, the effect of CA polymer concentrations at low acetyl group of $39.8 \%$ and casting thickness on the structure and morphologies of the membranes were studied. The CA polymer concentration was optimised from a range of $10 \mathrm{wt} \%, 15 \mathrm{wt} \%$ and $20 \mathrm{wt} \%$, and the casting thickness was optimised from a range of $150 \mu \mathrm{m}$ to $400 \mu \mathrm{m}$ using wet-phase inversion technique. The results obtained exhibit a CA membrane with thin dense, selective skin-layer achieved at CA polymer concentration of $15 \mathrm{wt} \%$ and a casting thickness of $300 \mu \mathrm{m}$, with a $\mathrm{CO}_{2}$ permeance rate of $401.173 \pm 0.579$ (GPU), $\mathrm{N}_{2}$ permeance rate of $133.499 \pm 0.148$ (GPU) and selectivity of $3.009 \pm 0.00656$. This $C A$ membrane is able to contribute to promising gas separation performances with enhanced physical and mechanical support by improvement of membrane permeance and selectivity towards $\mathrm{CO}_{2} / \mathrm{N}_{2}$ separation performance.
\end{abstract}

Keywords: Casting thickness, cellulose acetate, gas separation, membrane-based gas separation, polymer concentration 


\section{INTRODUCTION}

Carbon dioxide $\left(\mathrm{CO}_{2}\right)$ is the largest cause to global warming $(60 \%)$ amongst other greenhouse gases (GHGs) such as water vapour $\left(\mathrm{H}_{2} \mathrm{O}\right)$, methane $\left(\mathrm{CH}_{4}\right)$ and ozone. ${ }^{1}$ This is due to their longer atmospheric life span. ${ }^{2}$ It has been reported that atmospheric $\mathrm{CO}_{2}$ concentration has risen from $275 \mathrm{ppm}$ to $387 \mathrm{ppm}$ since the last century, which has led to increases in global temperatures. ${ }^{3}$ Compared with oil and gas, the least costly method to produce electricity is coal and it is predicted that global $\mathrm{CO}_{2}$ emissions from coal combustion will rise from 9Gt/year in 2000 to $32 \mathrm{G} \mathrm{t} /$ year in $2050 .{ }^{4}$ Separation of $\mathrm{CO}_{2}$ from flue gas at low partial pressures and low temperatures, after the fuel is completely combusted for energy conversion is known as post-combustion capture. The gas stream feeds at atmospheric pressure with low $\mathrm{CO}_{2}$ concentration ( $5 \%-25 \%$ is air used for combustion). ${ }^{5}$

Polymer membrane systems are highly encouraged in post-combustion capture of separating $\mathrm{CO}_{2}$ from flue gas by a modelling study of polymeric membranes in gas turbine power plants. One example of polymer used in $\mathrm{CO}_{2} / \mathrm{N}_{2}$ separations is cellulose acetate (CA), which amongst all other polymers used for the same purpose, has high $\mathrm{CO}_{2}$ solubility. ${ }^{6-8}$ The most desired membrane morphology in gas separating polymeric membranes is the asymmetric membrane with a thin dense skin layer. One variable that affects this is polymer concentration in the casting dope. According to Rajesh et.al, higher polymer concentrations can result in smooth dense top layer while lower polymer concentrations can result in an increase of the pore size. ${ }^{9}$ In addition, increasing polymer concentration might increase the casting dope viscosity which can result in decrease of pore size hence decreasing membrane porosity. ${ }^{10}$ Moreover, an increase in CA polymer concentration means higher acetyl content in the casting solution, thus the exhibition of plastic behaviour in the membranes, which can disrupt permeance and $\mathrm{CO}_{2} / \mathrm{N}_{2}$ selectivity. ${ }^{11}$

Another factor that can influence the membrane performance and structure is the casting thickness. A membrane needs a dense skin layer to build pressure, though overall dense skin layer thickness can restrict gas permeation. Based on Ahmad et al., when the casting thickness increased, the dense skin layer gets thicker and gas permeation reduced, but thinner membranes also results in lower mechanical strength and affects efficiency of gas separation. ${ }^{12}$ Other investigations also found that pore size increases with the membrane thickness while, selectivity decreases with pore size. This shows that to keep high selectivity, manufacturers must have stringent control over the membrane pore diameter. ${ }^{13}$ 
Thus, this research aims to develop a thin, defect-free asymmetric membrane with dense skin layer using CA polymer with $39.8 \%$ acetyl group. Up to date, there are no studies on the influence of CA polymer concentration (10-20 wt $\%)$ and the casting thickness $(150-400 \mu \mathrm{m})$ on the $\mathrm{CO}_{2}$ permeance and $\mathrm{CO}_{2} / \mathrm{N}_{2}$ selectivity.

\section{EXPERIMENTAL}

\subsection{Materials}

CA with acetyl content of 38\%-39.8\% was acquired from Sigma Aldrich (Malaysia). Acetic acid $\left(\mathrm{CH}_{3} \mathrm{COOH}\right)$ ACS reagent $\geq 99.7 \%$ was supplied from Sigma Aldrich (Malaysia). Ethanol and n-Hexane obtained from Merck (Malaysia). Purified $\mathrm{CO}_{2}$ and $\mathrm{N}_{2}$ were acquired from Linde EOX Sdn Bhd (Malaysia).

\subsection{Preparation of CA Membrane (CA-M)}

The casting solution was prepared by mixing $10 \mathrm{wt} \% \mathrm{CA}, 63 \mathrm{wt} \% \mathrm{CH}_{3} \mathrm{COOH}$ and $27 \mathrm{wt} \%$ of deionised water. The mixing was done by stirring the solution for $3 \mathrm{~h}$ with a magnetic stirrer at temperature of $55^{\circ} \mathrm{C}$ for complete dissolving and uniform mixing. The solution was then kept into $100 \mathrm{ml}$ Duran bottle and left to cool at room temperatures of $27^{\circ} \mathrm{C}$ for a $24 \mathrm{~h}$ period. The ultrasonic degasser was then used to eliminate existing gas bubbles in a 20 min duration after the cooling period was completed. ${ }^{14}$

The membrane was cast using an automatic film applicator situated in a fume chamber at room temperatures with casting thickness of $250 \mu \mathrm{m}$. After the film was formed, the membrane was directly immersed into a coagulation bath of deionised water for $24 \mathrm{~h}$ to remove excess solvent content. ${ }^{12,14,15}$ Membrane drying was then conducted using the solvent exchange method by immersing the span membrane in ethanol solution for $4 \mathrm{~h}$ followed by $\mathrm{n}$-hexane solution for $1 \mathrm{~h} .^{12,14}$ Lastly, the membrane film was placed in between two glass plates for a period of $24 \mathrm{~h}$ prior to use. ${ }^{12}$

\subsection{Effect of Polymer Concentration}

To determine the influence of polymer concentration on the membrane performance, different CA polymer concentrations (10-20 wt \%) were used as tabulated in Table 1. 
Table 1: Compositions of membrane prepared at different CA polymer concentrations.

\begin{tabular}{cccccc}
\hline $\begin{array}{c}\text { Membrane } \\
\text { sample }\end{array}$ & $\begin{array}{c}\mathrm{CA} \\
(\mathrm{wt} \%)\end{array}$ & $\begin{array}{c}\mathrm{CH}_{3} \mathrm{COOH} \\
(\mathrm{wt} \%)\end{array}$ & $\begin{array}{c}\mathrm{H}_{2} \mathrm{O} \\
(\mathrm{wt} \%)\end{array}$ & $\begin{array}{c}\text { Acetyl content } \\
(\mathrm{wt} \%)\end{array}$ & $\begin{array}{c}\text { Casting thickness } \\
(\mu \mathrm{m})\end{array}$ \\
\hline M1 & 10 & 63 & 27 & 3.98 & 250 \\
M2 & 15 & 59.5 & 25.5 & 5.97 & 250 \\
M3 & 20 & 56 & 24 & 7.96 & 250 \\
\hline
\end{tabular}

\subsection{Effect of Casting Thickness}

In this section, membranes were prepared at casting thickness of $150 \mu \mathrm{m}$ (M4), $250 \mu \mathrm{m}$ (M2), $300 \mu \mathrm{m}$ (M5) and $400 \mu \mathrm{m}$ (M6) as demonstrated in Table 2.

Table 2: Compositions of membrane prepared at different casting thickness.

\begin{tabular}{cccccc}
\hline $\begin{array}{c}\text { Membrane } \\
\text { sample }\end{array}$ & $\begin{array}{c}\mathrm{CA} \\
(\mathrm{wt} \%)\end{array}$ & $\begin{array}{c}\mathrm{CH}_{3} \mathrm{COOH} \\
(\mathrm{wt} \%)\end{array}$ & $\begin{array}{c}\mathrm{H}_{2} \mathrm{O} \\
(\mathrm{wt} \%)\end{array}$ & $\begin{array}{c}\text { Acetyl content } \\
(\mathrm{wt} \%)\end{array}$ & $\begin{array}{c}\text { Casting thickness } \\
(\mu \mathrm{m})\end{array}$ \\
\hline M4 & 15 & 59.5 & 25.5 & 5.97 & 150 \\
M2 & 15 & 59.5 & 25.5 & 5.97 & 250 \\
M5 & 15 & 59.5 & 25.5 & 5.97 & 300 \\
M6 & 15 & 59.5 & 25.5 & 5.97 & 400 \\
\hline
\end{tabular}

\subsection{Membrane Performance}

The membranes were tested based on a previously published work. ${ }^{14}$

\subsection{Membrane Characterisation Methods}

\subsubsection{SEM}

Scanning electron microscopy (TM3000 Tabletop SEM, USM-MTDC) was used to study the cast membrane morphology. The membrane samples were frozen at $-80^{\circ} \mathrm{C}$ to ensure an un-deformed structure when fractured into small pieces during membrane cracking. The small fractured pieces were platinum sputtercoated to limit sample charging and produce contradicting images. A double-sided conductive adhesive tape was used to hold the sample at the stainless-steel holder. Different zooming rates and high-resolution electrographs were used to obtain the surface morphology of the membranes. The thickness of the membrane structure and top skin layer were measured with ImageJ software (1.32j, United States). At least five samples were used to measure the dense skin layer. 


\subsubsection{Viscosity of casting solution}

The viscosity of the casting solution was tested using a viscometer (BROOKFIELD Viscometer, Mecomb Malaysia Sdn. Bhd.). The average viscosity was calculated from three samples and the standard errors were determined.

\section{RESULTS AND DISCUSSION}

\subsection{Effect of Polymer Concentration}

\subsubsection{Characterisation of membrane}

SEM was utilised to characterise the surface structure and cross-sectional morphologies of CA membranes at polymer concentration of $10 \mathrm{wt} \%$ (M1), $15 \mathrm{wt} \%(\mathrm{M} 2)$ and $20 \mathrm{wt} \%(\mathrm{M} 3)$.

Based on Figure 1( $a$ and $b$ ), a porous structure was observed on the surface of M1. The cross-sectional morphology also exhibits a dense skin-layer with a thickness of $27.28 \mu \mathrm{m}$. At a lower CA polymer concentration, water can quickly diffuse into the casting solution due to low polymer concentration, low viscosity and easy phase-separation. ${ }^{16}$ Figure 1(c and d) shows a smooth membrane surface on M2. A dense skin-layer is also observed in the cross-sectional morphology, with a thickness of $12.81 \mu \mathrm{m}$. When the polymer concentration was increased to $15 \mathrm{wt} \%$ (M2), the viscosity of the casting dope was enhanced, which led to the formation of a thinner and denser skin layer. This is because the viscosity of the casting dope is higher than of M1, which increased the precipitation rate and caused a faster phase-separation at the skin-layer. ${ }^{17}$ Figure 1(e and f) exhibits a smooth membrane surface on M3, with a skin-layer of $0.56 \mu \mathrm{m}$. It possesses the densest and thinnest skin-layer compared with M1 and M2. This resulted from the higher polymer concentration that increased the viscosity of the casting dope, which led to a formation of a denser membrane. When increasing the polymer concentration to $20 \mathrm{wt} \%$ (M3), the viscosity of the casting solution increased, thereby limiting the diffusion exchange rate of solvent and non-solvent, as tabulated in Table 3. This resulted in immediate phase separation at the skin-layer and slowed the precipitation rate which reduced the pore size in the membrane. ${ }^{17}$ Besides that, the higher polymer concentration caused the polymer chains to entangle at the top skin-layer, thus reducing the formation of macrovoids and producing a thinner, smoother skin-layer. ${ }^{17}$ 
Table 3: Viscosities of CA membrane casting dope.

\begin{tabular}{ccc}
\hline Sample & CA polymer concentration in casting dope $(\mathrm{wt} \%)$ & Viscosity $(\mathrm{cP})$ \\
\hline M1 & 10 & $91.735 \pm 0.391$ \\
M2 & 15 & $282.033 \pm 0.383$ \\
M3 & 20 & $571.68 \pm 2.872$ \\
\hline
\end{tabular}
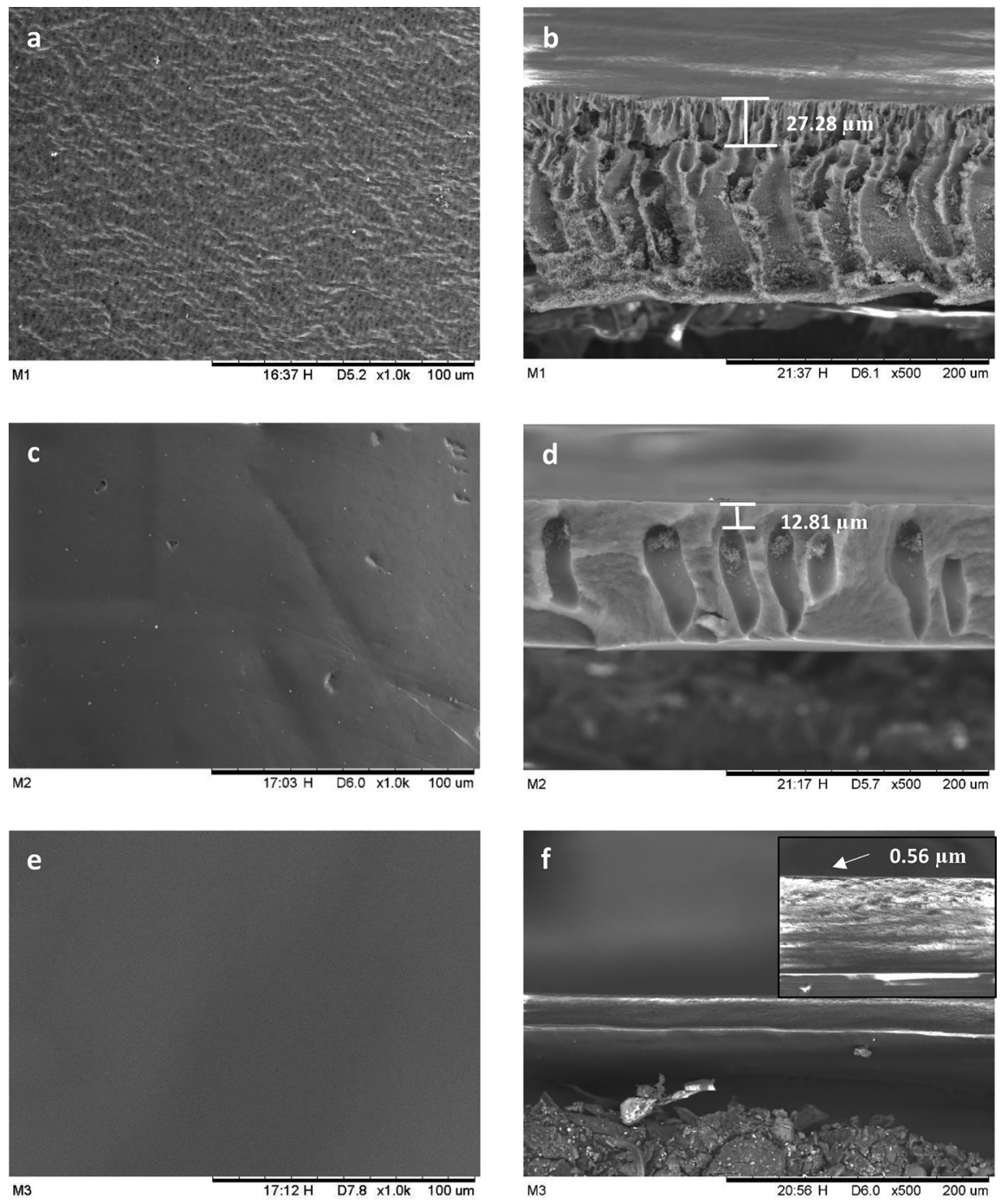

Figure 1: SEM micrographs of membrane surface and cross-sectional structure of membrane fabricated at CA polymer concentration of (a and b) $10 \mathrm{wt} \%$, M1; (c and d) $15 \mathrm{wt} \%, \mathrm{M} 2$; and (d and e) $20 \mathrm{wt} \%$, M3; at casting thickness of $250 \mu \mathrm{m}$. 


\subsection{2 $\mathrm{CO}_{2} / \mathrm{N}_{2}$ Separation Performance}

The membrane performance for gas separation was evaluated by conducting single gas permeation test for M1 (10wt \%), M2 (15 wt \%) and M3 (20 wt \%). Figure 2 illustrates that $\mathrm{M} 1$ has the highest $\mathrm{CO}_{2}$ permeance, which is around $304.249 \pm$ $1.955 \mathrm{GPU}$. This was due to the porous structure of the membrane at low CA polymer concentration $(10 \mathrm{wt} \%)$ as seen in Figure 1(a) that allows higher gas permeance. Meanwhile, the $\mathrm{CO}_{2}$ permeance of M2 and M3 are $253.773 \pm 0.773$ GPU and $8.735 \pm 0.00271$ GPU, respectively. As a result of the increment in the polymer concentration, the phase-separation at the skin-layer produced faster and a denser skin-layer formed. ${ }^{17}$ This agglomeration of polymer at higher polymer concentrations of $\mathrm{CA}$ at $20 \mathrm{wt} \%$ (M3) might reduce the formation of a porous support structure that provides the membrane mechanical strength. Thus, M3 was also able to only build-up pressure to 2.0 bar. Therefore, higher polymer concentrations produce membranes with lower permeance. ${ }^{18}$

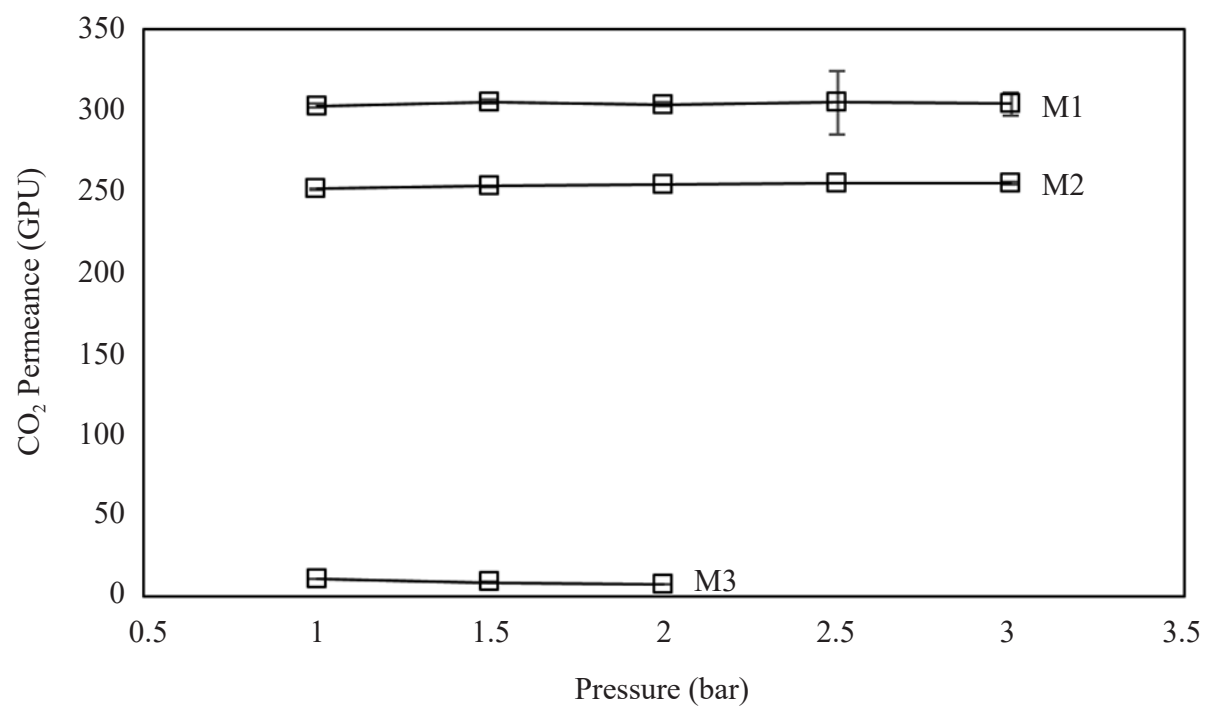

Figure 2: Single-gas permeance of $\mathrm{CO}_{2}$ for $\mathrm{CA}$ membranes at $\mathrm{CA}$ polymer concentrations of $10 \mathrm{wt} \%$ (M1), $15 \mathrm{wt} \%$ (M2) and $20 \mathrm{wt} \%$ (M3) at casting thickness of $250 \mu \mathrm{m}$.

The membranes were also subjected to $\mathrm{N}_{2}$ gas permeation test. Based on Figure 3, M1 (10 wt $\%$ ) possesses the highest $\mathrm{N}_{2}$ permeance rate of $194.463 \pm 0.667 \mathrm{GPU}$, followed by M2 (15 wt $\%)$ at a rate of $92.139 \pm 0.0844 \mathrm{GPU}$ and the lowest is M3 (20 wt\%) at $43.654 \pm 0.129$ GPU. Even though M1 has a thicker skin-layer $(27.28 \mu \mathrm{m})$ compared with M2 $(12.81 \mu \mathrm{m}), \mathrm{N}_{2}$ permeance has less resistance 
in M1. This is due to the porous structure of M1 as seen in Figure 1(a) which justifies the increase in gas permeation rate. When the polymer concentration increased to $15 \mathrm{wt} \%$ (M2), a denser skin layer was synthesised, which reduced the $\mathrm{N}_{2}$ permeance rate. Despite having the thinnest skin-layer of $0.56 \mu \mathrm{m}, \mathrm{M} 3 \mathrm{had}$ the lowest $\mathrm{N}_{2}$ permeance rate. Due to agglomeration of polymer chains at higher polymer concentrations, M3 (20 wt \%) possessed least porosity formation within the membrane that hinders $\mathrm{N}_{2}$ permeance rate. ${ }^{18}$

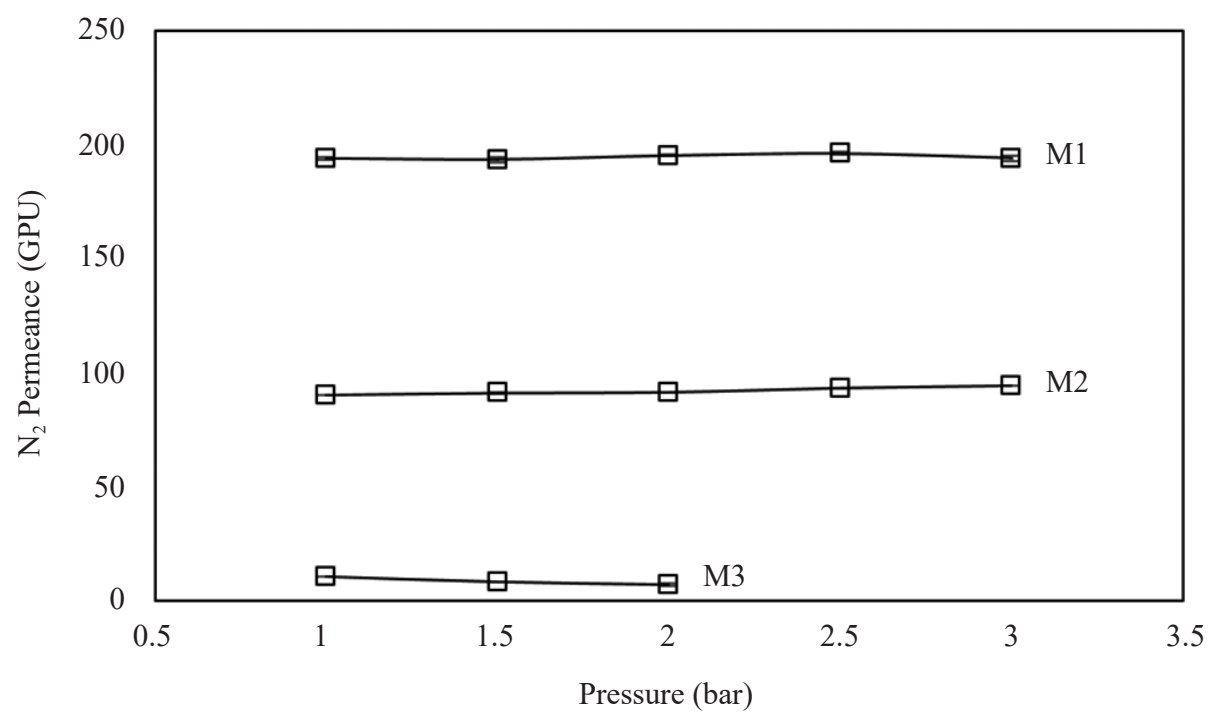

Figure 3: Single-gas permeance of $\mathrm{N}_{2}$ for $\mathrm{CA}$ membranes at $\mathrm{CA}$ polymer concentrations of $10 \mathrm{wt} \%$ (M1), $15 \mathrm{wt} \%$ (M2) and $20 \mathrm{wt} \%$ (M3) at casting thickness of $250 \mu \mathrm{m}$.

The $\mathrm{CO}_{2} / \mathrm{N}_{2}$ selectivity of $\mathrm{CA}$ membranes prepared at various polymer concentrations was studied as illustrated in Figure 4. This figure demonstrates that CA polymer concentration of $15 \mathrm{wt} \%$ (M2) has the highest selectivity performance, which is $2.761 \pm 0.00375$. M2 possessed a smooth, selective dense skin-layer morphology, shown in Figure 1(c and d), which increased the $\mathrm{CO}_{2} / \mathrm{N}_{2}$ selectivity. Meanwhile, the selectivity performance of M1 is $1.1562 \pm 0.0312$ and the lowest is $\mathrm{M} 30.199 \pm 0.000498$. At lower polymer concentration of $10 \mathrm{wt} \%$ (M1), the membrane produced a porous structure, which increased the $\mathrm{N}_{2}$ permeance and decreased the effectiveness of the selective skin-layer, thus reducing the $\mathrm{CO}_{2} / \mathrm{N}_{2}$ selectivity. When the polymer concentration was increased to $20 \mathrm{wt} \%$ (M3), the membrane produced a smooth and thinnest skin-layer with low porosity, shown in Figure 1(f), thus reducing the effectiveness of the selective skin-layer and resulting in a poor gas-separation performance. 


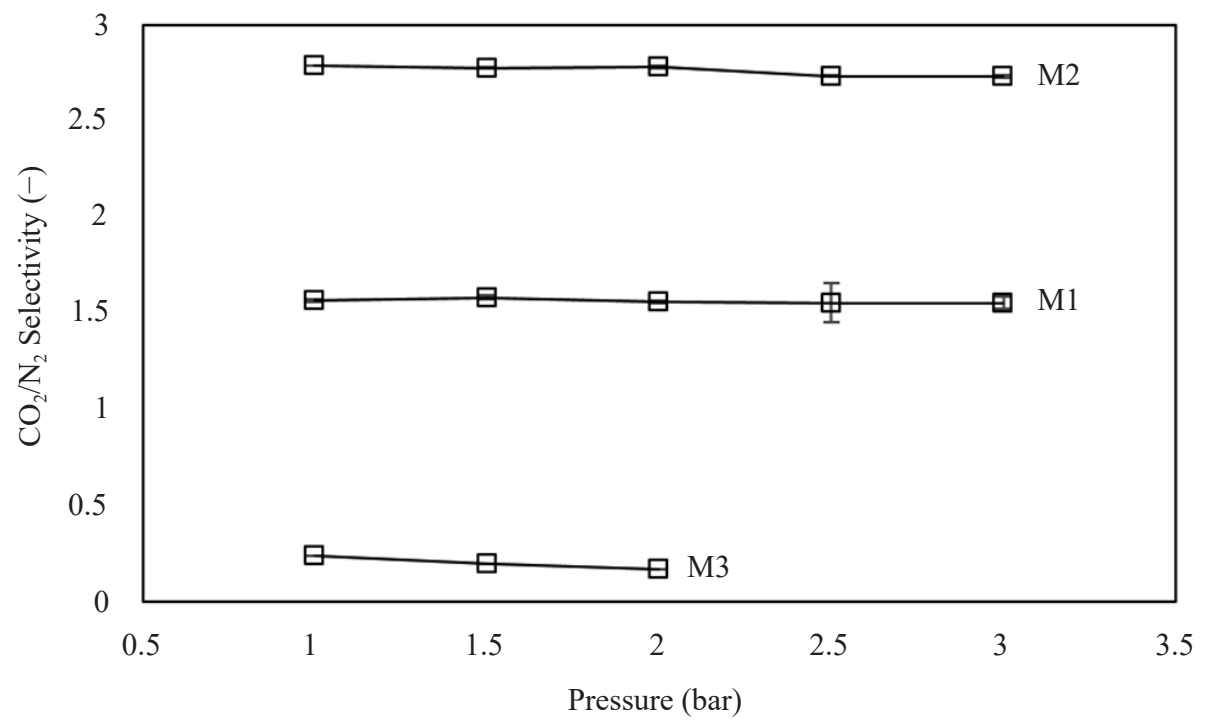

Figure 4: $\quad \mathrm{CO}_{2} / \mathrm{N}_{2}$ ideal selectivity for CA membranes at CA polymer concentrations of $10 \mathrm{wt} \%$ (M1), $15 \mathrm{wt} \%$ (M2) and $20 \mathrm{wt} \%$ (M3) at casting thickness of $250 \mu \mathrm{m}$.

\subsection{Effect of Casting Thickness}

\subsubsection{Characterisation of membrane}

The morphologies of membrane casted at different casting thickness of $150 \mu \mathrm{m}$ (M4), $250 \mu \mathrm{m}$ (M2), $300 \mu \mathrm{m}$ (M5) and $400 \mu \mathrm{m}$ (M6) at the optimised CA polymer concentration of $15 \mathrm{wt} \%$ are presented in Figure 5.

Figure 5 demonstrates smooth membrane surfaces, with dense skin-layer thickness of $10.39 \mu \mathrm{m}, 12.81 \mu \mathrm{m}$ and $13.48 \mu \mathrm{m}$ for M4, M2 and M5, respectively. As the casting thickness increases, the deposition speed of the polymer in the film reduced and more layers participated in the formation of the membrane. ${ }^{18}$ There is also delayed kinetics in phase separation that allows the merging of domains that are polymer-lean below the membrane and air interface, thus resulting in more compaction of the polymer matrix. ${ }^{14,18}$ As seen in Figure 5(g), M6 $(400 \mu \mathrm{m})$ possesses a porous surface and has a dense skin-layer at thickness of $19.72 \mu \mathrm{m}$. This porous structure is formed due to the diffusion and displacement between the solvent and non-solvent regions in the casting film. The polymer deposition speed was slower due to more layers involved in the membrane formation. Thus, large amounts of water can diffuse into the polymer matrix and form larger pores in the skin layer. ${ }^{18}$ 

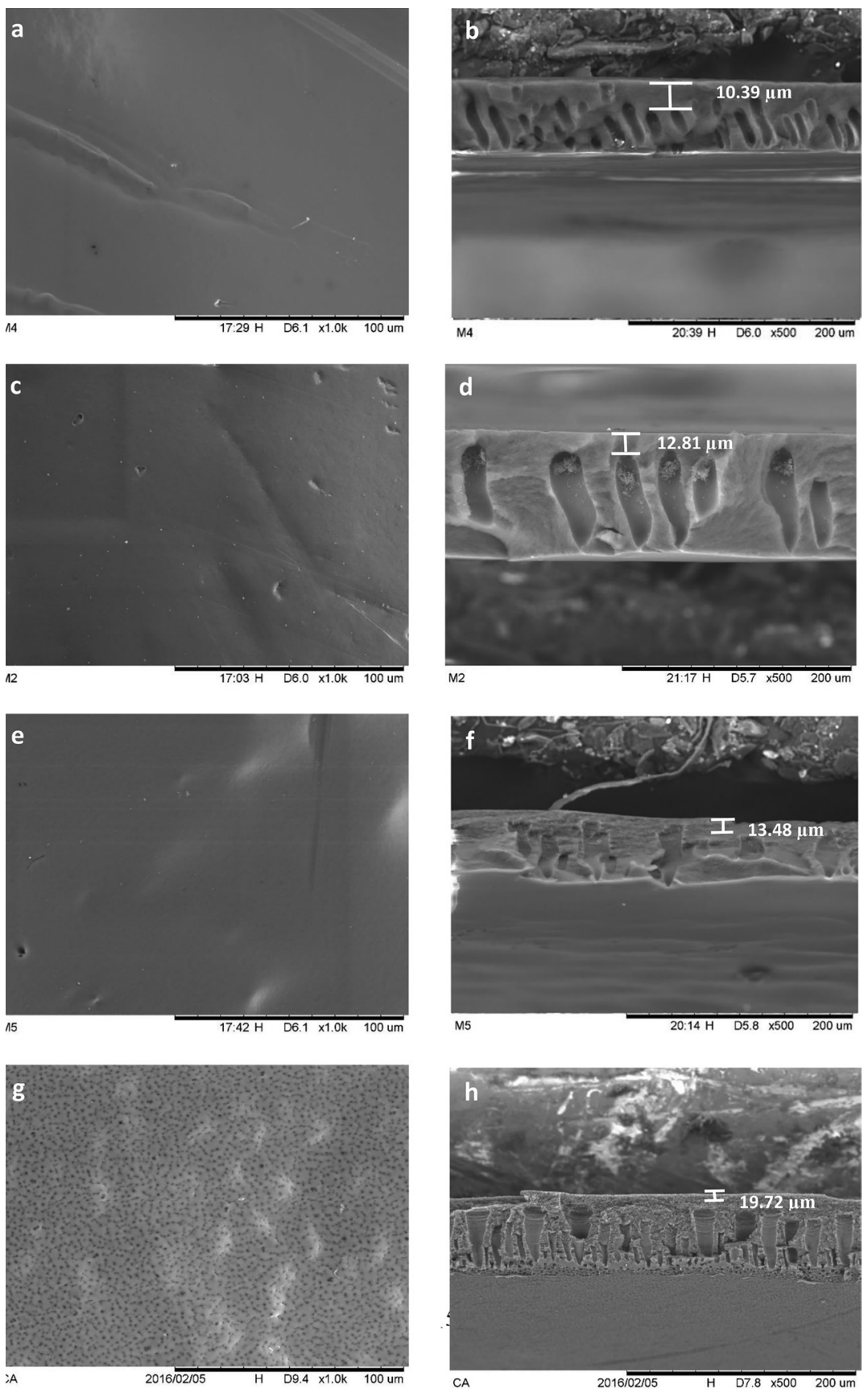

Figure 5: SEM micrographs of membrane surface and cross-sectional structure of CA membrane fabricated at casting thickness of (a and b) $150 \mu \mathrm{m}, \mathrm{M} 4$; (c and d) $250 \mu \mathrm{m}, \mathrm{M} 2$; (e and f) $300 \mu \mathrm{m}, \mathrm{M} 5$; and (g and h) $400 \mu \mathrm{m}, \mathrm{M} 6$. 


\subsection{2 $\mathrm{CO}_{2} / \mathrm{N}_{2}$ Separation Performance}

The $\mathrm{CO}_{2}$ permeation of M2 $(250 \mu \mathrm{m}), \mathrm{M} 4(150 \mu \mathrm{m}), \mathrm{M} 5(300 \mu \mathrm{m})$ and M6 $(400 \mu \mathrm{m})$ are demonstrated in Figure 6. Based on Figure 6, M4 $(150 \mu \mathrm{m})$ has the highest $\mathrm{CO}_{2}$ permeance, which is $428.541 \pm 0.974 \mathrm{GPU}$. Meanwhile, the $\mathrm{CO}_{2}$ permeance of M2 $(250 \mu \mathrm{m}), \mathrm{M} 5(300 \mu \mathrm{m})$ and M6 $(400 \mu \mathrm{m})$ are $253.773 \pm 0.773$ GPU, $401.173 \pm 0.579$ GPU and $11.895 \pm 0.00665$ GPU, respectively. These results are in line with the formation of the dense skin layer of the membrane, shown in Figure 5(b, d, f and h).

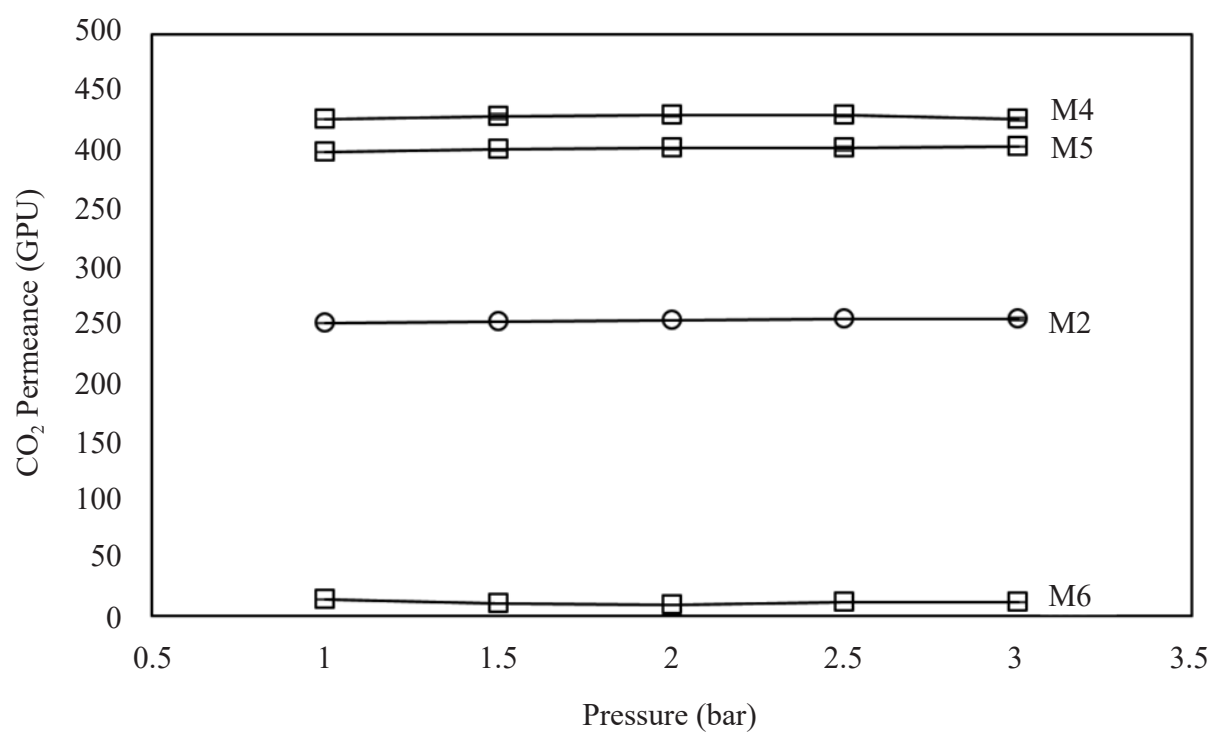

Figure 6: Single-gas permeance of $\mathrm{CO}_{2}$ for $\mathrm{CA}$ membranes at casting thickness of $150 \mu \mathrm{m}$ (M4), $250 \mu \mathrm{m}$ (M2), $300 \mu \mathrm{m}$ (M5) and $400 \mu \mathrm{m}$ (M6) with CA polymer concentration of $15 \mathrm{wt} \%$.

The membranes were also subjected to $\mathrm{N}_{2}$ gas permeation test as seen in Figure 7. It was observed that M4 $(150 \mu \mathrm{m})$ demonstrated the highest $\mathrm{N}_{2}$ permeance rate of $363.910 \pm 0.258 \mathrm{GPU}$, followed by M5 $(300 \mu \mathrm{m})$ at a rate of $133.499 \pm 0.148 \mathrm{GPU}, \mathrm{M} 2(250 \mu \mathrm{m})$ at $92.139 \pm 0.0844 \mathrm{GPU}$ and the lowest, M6 $(400 \mu \mathrm{m})$ at $27.332 \pm 0.0757 \mathrm{GPU}$. At lower casting thickness of $150 \mu \mathrm{m}$ (M4), the membrane formed a thin selective skin layer with thickness of $10.39 \mu \mathrm{m}$, thus resulting in higher gas permeance. As the casting thickness increased to $250 \mu \mathrm{m}(\mathrm{M} 2)$ and $300 \mu \mathrm{m}(\mathrm{M} 5), \mathrm{N}_{2}$ permeance decreased. This is because as the thickness of the selective layer increased in M2 to $12.82 \mu \mathrm{m}$ and M5 to $13.48 \mu \mathrm{m}$, the gas permeance decreased. When the casting thickness is increased to $400 \mu \mathrm{m}$ 
(M6), more layers are involved and produced a thicker skin-layer which hinders gas permeance. Thus, increasing casting thickness would increase the thickness of dense skin-layer but decreases the gas permeance rate. ${ }^{14}$

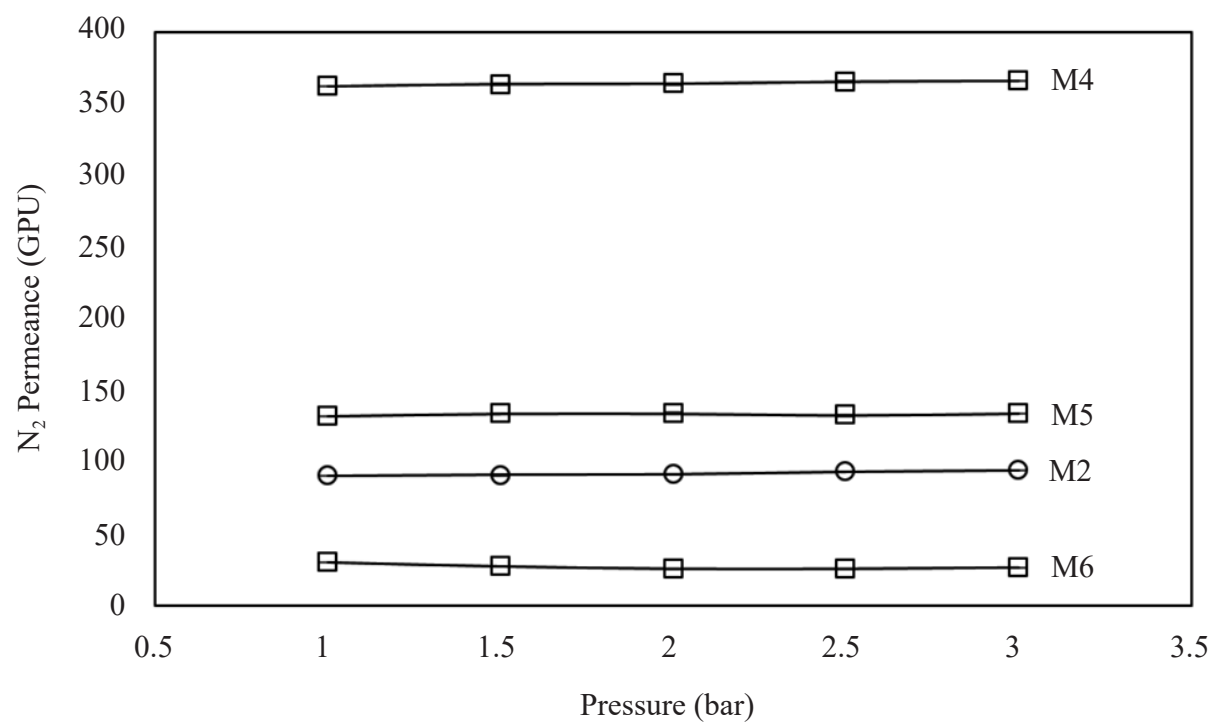

Figure 7: Single-gas permeance of $\mathrm{N}_{2}$ for $\mathrm{CA}$ membranes at casting thickness of $150 \mu \mathrm{m}$ (M4), $250 \mu \mathrm{m}$ (M2), $300 \mu \mathrm{m}$ (M5) and $400 \mu \mathrm{m}$ (M6) with CA polymer concentration of $15 \mathrm{wt} \%$.

Based on Figure 8, CA membranes prepared with casting thickness of $300 \mu \mathrm{m}$ (M5) proved the best $\mathrm{CO}_{2} / \mathrm{N}_{2}$ selectivity performance of $3.009 \pm 0.00656$ as compared to M4 $(150 \mu \mathrm{m}), \mathrm{M} 2(250 \mu \mathrm{m})$ and $\mathrm{M} 6(400 \mu \mathrm{m})$ with $\mathrm{CO}_{2} / \mathrm{N}_{2}$ selectivity of $1.179 \pm 0.00250,2.761 \pm 0.00375$ and $0.435 \pm 0.00134$, respectively. This was due to the homogeneous distribution of the finger-like macrovoids in M5 $(300 \mu \mathrm{m})$, as shown in Figure 6(h). After this casting thickness, defects formed in these macrovoids (M6, Figure 6(h)), resulting in poor separation performance. In conclusion, $\mathrm{M} 5(300 \mu \mathrm{m})$ has the best $\mathrm{CO}_{2} / \mathrm{N}_{2}$ selectivity separation performance amongst all the CA membranes prepared. Hence, the optimised casting thickness is $300 \mu \mathrm{m}$. 


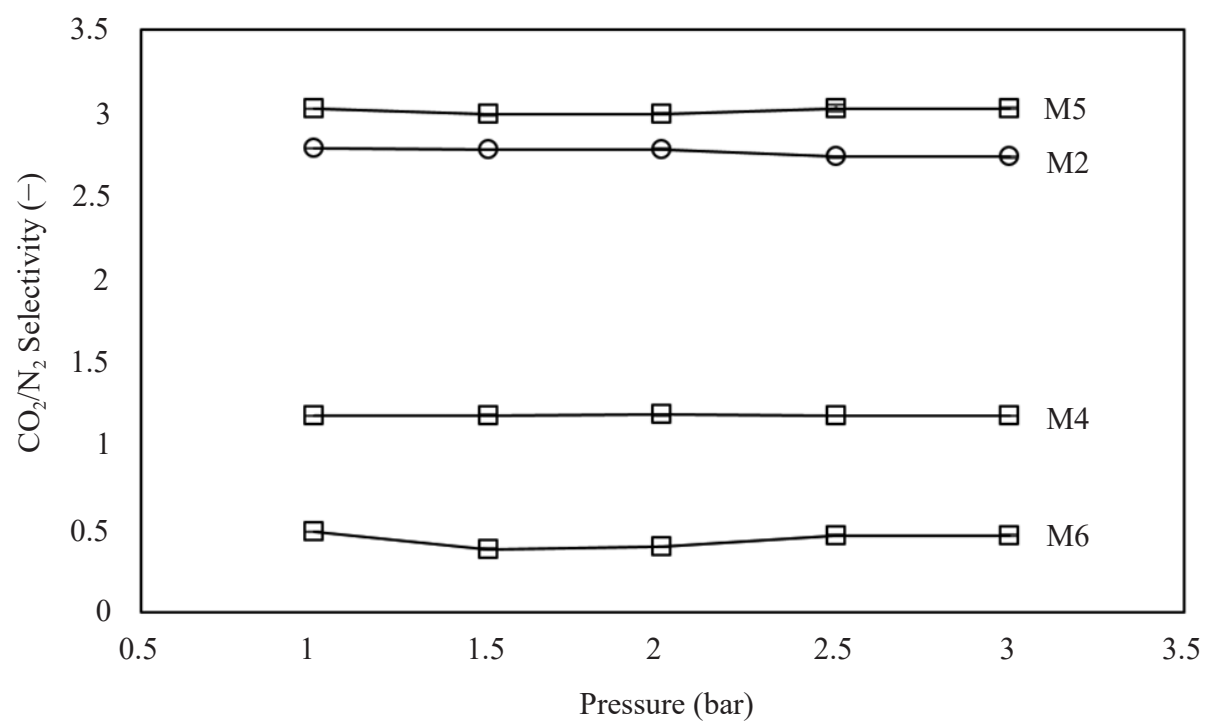

Figure 8: $\quad \mathrm{CO}_{2} / \mathrm{N}_{2}$ ideal selectivity of $\mathrm{CA}$ membranes prepared at casting thickness of $150 \mu \mathrm{m}$ (M4), $250 \mu \mathrm{m}$ (M2), $300 \mu \mathrm{m}$ (M5) and $400 \mu \mathrm{m}$ (M6) with CA polymer concentration of $15 \mathrm{wt} \%$.

\section{CONCLUSION}

In this research project, the $\mathrm{CO}_{2} / \mathrm{N}_{2}$ separation performance proved that $\mathrm{CA}$ polymer concentration and membrane casting thickness affects the physical structure, permeance and selectivity of the CA membrane. The optimal CA polymer concentration was found to be $15 \mathrm{wt} \%$ (M2), which exhibited a $\mathrm{CO}_{2}$ permeance rate of $253.773 \pm 0.276(\mathrm{GPU})$ and $\mathrm{N}_{2}$ permeance rate of $92.139 \pm 0.0844$ (GPU). This resulted in highest $\mathrm{CO}_{2} / \mathrm{N}_{2}$ selectivity of $2.761 \pm 0.00375$. M2 was then used to study the membrane casting thickness performances. The optimal casting thickness was found to be at $300 \mu \mathrm{m}$ (M5). M5 demonstrated a $\mathrm{CO}_{2}$ permeance rate of $401.173 \pm 0.579$ (GPU) and $\mathrm{N}_{2}$ permeance rate of $133.499 \pm 0.148$ (GPU). This resulted in the highest $\mathrm{CO}_{2} / \mathrm{N}_{2}$ selectivity of $3.009 \pm 0.00656$. Based on the results obtained, the best membrane was formed with a smooth surface, dense selective skin layer and a porous bottom layer that provided mechanical strength, which gave the desired $\mathrm{CO}_{2} / \mathrm{N}_{2}$ separation. 


\section{ACKNOWLEDGEMENTS}

The authors would like to offer their appreciation to the Ministry of Higher Education Malaysia (MOHE) for approving Fundamental Research Grant Scheme (FRGS) (MOHE ref. no. FRGS/1/2015/TK02/CURTIN/03/01) and Cost Centre: 001048. We would also like to thank Long Term Research Grant Scheme (LRGS), Universiti Sains Malaysia (account no. 304/PJKIMIA/6050296/U124) and Curtin Cost Centre: 001047.

\section{REFERENCES}

1. Yamasaki, A. (2003). An overview of $\mathrm{CO}_{2}$ mitigation options for global warmingemphasizing $\mathrm{CO}_{2}$ sequestration options. J. Chem. Eng. Jap., 36, 361-375, https://doi.org/10.1252/jcej.36.361.

2. Archer, D. \& Brovkin, V. (2008). The millennial atmospheric lifetime of anthropogenic $\mathrm{CO}_{2}$. Clim. Change, 90, 283-297, https://doi.org/10.1007/s10584008-9413-1.

3. Merkel, T. C. et al. (2010). Power plant post-combustion carbon dioxide capture: An opportunity for membranes. J. Membr. Sci., 359, 126-139, https://doi. org/10.1016/j.memsci.2009.10.041.

4. Harding, J. (2007). Economics of nuclear power and proliferation risks in a carbonconstrained world. Electr. J., 20, 65-76, https://doi.org/10.1016/j.tej.2007.10.012.

5. Favre, E. (2007). Carbon dioxide recovery from post-combustion processes: Can gas permeation membranes compete with absorption? J. Membr. Sci., 294, 50-59, https://doi.org/10.1016/j.memsci.2007.02.007.

6. Carapellucci, R. \& Milazzo, A. (2003). Membrane systems for $\mathrm{CO}_{2}$ capture and their integration with gas turbine plants. Proc. Inst. Mech. Eng. A JPEE, 217, 505-517, http://dx.doi.org /10.1243/095765003322407557.

7. Powell, C. E. \& Qiao, G. G. (2006). Polymeric $\mathrm{CO}_{2} / \mathrm{N}_{2}$ gas separation membranes for the capture of carbon dioxide from power plant flue gases. J. Membr. Sci., 279, 1-49, https://doi.org/10.1016/j.memsci.2005.12.062.

8. Spillman, R. \& Cooley, T. (1987). Economic considerations in membrane gas separation process design. New York: AIChE.

9. Rajesh, S. et al. (2011). Preparation and characterisation of poly (amide-imide) incorporated cellulose acetate membranes for polymer enhanced ultrafiltration of metal ions. Chem. Eng. J., 171, 33-44, https://doi.org/10.1016/j.cej.2011.03.033.

10. Ngang, H. et al. (2012). Preparation of mixed-matrix membranes for micellar enhanced ultrafiltration based on response surface methodology. Desalin., 293, 7-20, https://doi.org/10.1016/j.desal.2012.02.018.

11. Coltelli, M. B. et al. (2008). Poly (lactic acid) properties as a consequence of poly (butylene adipate-co-terephthalate) blending and acetyl tributyl citrate plasticization. J. Appl. Polym. Sci., 110, 1250-1262, https://doi.org/10.1002/ app.28512. 
12. Ahmad, A. et al. (2014). A cellulose acetate/multi-walled carbon nanotube mixed matrix membrane for $\mathrm{CO}_{2} / \mathrm{N}_{2}$ separation. J. Membr. Sci., 451, 55-66, https://doi. org/10.1016/j.memsci.2013.09.043.

13. Murad, S. \& Nitsche, L. C. (2004). The effect of thickness, pore size and structure of a nanomembrane on the flux and selectivity in reverse osmosis separations: A molecular dynamics study. Chem. Phys. Lett., 397, 211-215, https://doi.org/ 10.1016/j.cplett.2004.08.106.

14. Jawad, Z. et al. (2015). Incorporation of inorganic carbon nanotubes fillers into the CA polymeric matrix for improvement in $\mathrm{CO}_{2} / \mathrm{N}_{2}$ separation. Curr. Nanosci., 11, 69-79.

15. Zhang, X. R. et al. (2011). One-step fabrication and analysis of an asymmetric cellulose acetate membrane for heat and moisture recovery. J. Membr. Sci., 366, 158-165, https://doi.org/10.1016/j.memsci.2010.09.054.

16. Xing, D. Y., Peng, N. \& Chung, T. S. (2010). Formation of cellulose acetate membranes via phase inversion using ionic liquid,[BMIM] SCN, as the solvent. Inl. Eng. Chem. Res., 49, 8761-8769, https://doi.org/10.1021/ie1007085.

17. Sofiah, H., Nora'aini, A. \& Marinah, M. (2010). The influence of polymer concentration on performance and morphology of asymmetric ultrafiltration membrane for lysozyme separation. J. Appl. Polym. Sci., 10, 3325-3330.

18. Ahmad, A., Low, S. \& Shukor, S. A. (2007). Effects of membrane cast thickness on controlling the macrovoid structure in lateral flow nitrocellulose membrane and determination of its characteristics. Scr. Mater, 57, 743-746, https://doi. org/10.1016/j.scriptamat.2007.06.037. 